\title{
Down-Regulation of Death Receptor-5 in Metastatic Cascade of Triple-Negative Breast Cancer
}

\author{
(D) Mohammad Kamalabadi FARAHANI ${ }^{1,2}$ \\ 'Department of Tissue Engineering and Applied Cell Sciences, Tehran University of Medical Sciences, Faculty of Advanced \\ Technologies in Medicine, Tehran-Iran \\ ${ }^{2}$ Department of Tissue Engineering, Faculty of Medicine, Shahroud University of Medical Sciences, Shahroud-Iran
}

\begin{abstract}
OBJECTIVE
Metastasis is a major cause of fatality in Triple-Negative Breast Cancer (TNBC). There is a significant correlation between metastasis and chemoresistance in cancers. Evasion during apoptosis, considered as a hallmark of cancer, is a critical characteristic of metastatic tumor cells and the main cause of chemoresistance. In metastatic tumor cells, elucidating the mechanisms of apoptosis resistance is crucial to developing novel therapeutic strategies. In this study, we studied the expression of death receptors-5 (DR-5) as an execution factor of apoptosis in the metastatic cascade of TNBC.
\end{abstract}

\section{METHODS}

Using a 4T1 cell line, the animal model of metastatic breast cancer was made. Primary and metastatic tumor cells were extracted from subcutaneous tumor and lung of cancerous mice, respectively. Realtime PCR was performed to analyze the level of DR-5 gene expression.

\section{RESULTS}

Cell culture results demonstrated that metastatic tumor cells had comparatively greater proliferation potential. Moreover, Real-time analysis indicated that DR-5 expression in metastatic tumor cells was significantly reduced.

\section{CONCLUSION}

These findings provide important insights regarding the molecular mechanism of apoptosis resistance phenomenon in metastatic tumor cells and can partly explain the reasons for the chemoresistance in metastatic cells, which will highly likely to provide the basis for designing targeted therapeutic methods to overcome chemoresistance and combat with metastatic TNBC.

Keywords: Apoptosis; chemoresistance; DR-5; metastasis; triple-negative breast cancer. Copyright $\odot$ 2020, Turkish Society for Radiation Oncology

\section{Introduction}

Breast cancer is the most common cancer in women worldwide. Triple-negative breast cancer (TNBC) is the most aggressive and invasive type of breast cancer with poor prognosis. Anthracyclines-based combination chemotherapy is the standard treatment for patients with TNBC.[1] Targeted treatments essentially improve the patient's outcome for some types of breast cancer. However, in particular, TNBC has faced some potential challenges. Novel treatment strategies for TNBC use have targeted therapies in combination with apoptotic ligands, such as TRAIL and chemotherapy. However, the recurrence and metastasis of TNBC 
due to chemoresistance takes place in up to $70 \%$ of the patients.[2]

Metastases account for $90 \%$ of human cancer deaths. In cancer, metastasis and resistance to chemotherapy are linked phenomena.[3] Especially in breast cancer, metastasis is a major cause of fatality. Bone, lung and liver are the main sites of metastases in this disease. [4] Chemoresistance often hampers tumor cells from undergoing sufficient levels of apoptosis, resulting in cancer cell survival and treatment failure.[5] Chemotherapy, as well as targeted therapies, is aimed to reduce cell growth, survival, and metastasis and inducing apoptosis in breast cancer cells. However, their effectiveness is limited to the development of resistance and tumor progression. The molecular mechanisms that lead to therapeutic resistance are diverse and often involve apoptosis at various levels in signal cascades and are still incompletely understood.[6]

The apoptosis or programmed cell death is considered as an important homeostatic mechanism that equilibrates cell generation with cell death and maintains correct cell numbers in the body in physiological and pathological conditions.[7] Two fundamentally distinct apoptotic signaling pathways have been determined in mammalian cells: extrinsic (or death receptor pathway) and intrinsic (or mitochondrial) pathways. [8] The extrinsic pathway involves the activation of death receptors (DRs). The DRs are members of the tumor necrosis factor receptor superfamily and include a subfamily that is characterized by an intracellular death domain. Among all the DRs, DR- 4 and DR- 5 are selectively expressed in cancer cells and, thus, offer an advantage for targeted therapy and prevention. $[9,8]$

In the metastatic cascade, certain tumor cells detach from the primary tumor, circulate in the bloodstream and finally exit from the blood and constitute a new tumor inappropriate tissue. Tumor cells in different steps of these processes have distinctive and appropriative properties that will help them during this process. [10]

Identification of these specific features could be useful in the designing of new therapies. Several studies have focused on the molecular level of the metastasis process.[11,12] Metastatic cells tend to exhibit a higher survival ability and resistance to apoptosis and become resistant to treatment. It is postulated that the increase in apoptotic resistance of metastatic cancer cells is associated with modifying expression levels or function of proteins involved in apoptosis signaling pathways.[13]

There is little direct experimental evidence linking apoptosis and metastasis, the apoptotic resistance of metastatic cells were hence the focus of this study. We created a lung metastatic mice model of TNBC. Primary and metastatic tumor cells were generated and the expression of the DR5 as an execution factor of apoptosis was compared between these cells.

\section{Materials and Methods}

\section{Cell Culture}

4T1 cell line was purchased from the cell bank of Pasteur Institute of Iran. The cells were cultured in high glucose Dulbecco's Modified Eagle's Medium (DMEM) containing 10\% FBS (fetal bovine serum) and 2\% Penicillin-Streptomycin (all from Gibco, USA) in humidified atmosphere and $5 \% \mathrm{CO}_{2}$ at $37 \mathrm{C}$.

\section{Induction of Syngeneic Animal Model of Breast Cancer}

Female BALB/c mice weighing 20 to 25 gram was obtained from Royan Institute of Iran. The animals were housed in cages at 12-h photoperiod and free access to food and water. All animal experiments were in compliance with the relevant laws and were approved by the Ethics Committee of the Tehran University of Medical Sciences (registration number: IR.TUMS. REC.1394.1439). 4T1 cells were subcutaneously injected to the flank (OR the right hind limb) of the mice (105 cells suspended in $100 \mu \mathrm{L}$ PBS) using an insulin syringe with a $32 \mathrm{~g}$ needle. The mice were monitored daily for appearance and behavior characteristics.

\section{Lung Metastatic and Primary Breast Tumor Cell Extraction}

For extraction of the primary and metastatic tumor cells, after 35 days of tumor induction in mice, primary tumor and lung of cancerous mice were excised and surface blood was removed by rinsing in PBS. After mincing with scissors, fragments were placed into a $50 \mathrm{ml}$ conical tube. For enzymatic digestion, the primary tumor and the lungs were digested in 10 $\mathrm{mg} / \mathrm{ml}$ collagenase type IV at $37^{\circ} \mathrm{C}$ for $75 \mathrm{~min}$ on a platform rocker. All enzymes were purchased from Sigma (St Louis, MO, USA). The digested organ, filtered through 70-um cell strainers and washed twice with PBS. Cells were resuspended in medium containing 10\% FBS and 2\% Penicillin-Streptomycin and cultured in a cell culture flask in the humidified atmosphere and $5 \% \mathrm{CO}_{2}$ at $37^{\circ} \mathrm{C}$. The metastatic tumor cells in the lung, after primary isolation, form colonies in the culture medium. Due to the high rate of growth and proliferation, the tumor cells in these 
colonies are purified after several passages. These metastatic tumor cells are called 4T1L, while tumor cells obtained in the same way as the original tissue of the tumor called 4T1P.

\section{Quantification of DR5 by RT-qPCR}

The real-time PCR procedure was executed based on the $1 \mu \mathrm{g} / \mu \mathrm{l}$ cDNA in all samples. The primary and lung metastatic mammary tumor cells (4T1P and $4 \mathrm{~T} 1 \mathrm{~L}$ ) were grown in $6 \mathrm{~cm}$ Petri dishes to $80 \%$ confluence. Total RNA was extracted from these cells using QIAzol Lysis Reagent-QIAGEN. The RNA quality, yield, and size of extracted RNA were analyzed using nanodrop and electrophoresis. The first-strand cDNA synthesis was performed with the reverse transcription system (PrimeScript ${ }^{\mathrm{Tm}}$ RT reagent Kit (Perfect Real Time) Takara). Quantization of all gene transcripts was done by real-time quantitative PCR using Power SYBR Green PCR Master Mix and an RT-qPCR analysis for DR-5 was carried out with SYBR Green Realtime PCR Master Mix (Amplicon A/S, Denmark) according to the respective manufacturer's instruction. The exact mRNA expression was normalized to the expression level of GAPDH. Relative changes in gene expression were calculated by the following formula, and the data were represented as fold up-regulation/ down-regulation.

Fold change $=2-\Delta \Delta \mathrm{Ct}$, where $\Delta \Delta \mathrm{Ct}=[\mathrm{Ct}$ of gene of DR (in 4T1L)-Ct of gene GAPDH (in 4T1L)]-[Ct of gene of DR (in 4T1P)-Ct of gene GAPDH (in 4T1P)]

The primers used were as follows: for DR5, forward 5'-AAAACGGCTTGGGCATCTTGGC-3'; reverse5' AGACGGTTCCAGGAGTCAAAGG-3'; for GADPH, forward 5'-GGTGAAGGTCGGTGTGAACG-3'; reverse 5'-CTCGCTCCTGGAAGATGGTG-3'.

\section{RNA and DNA Gel Electrophoresis Assay}

Total extracted RNA from treated cells and real-time PCR, DNA products were electrophoresed on $1.2 \%$ agarose gel containing $0.5 \mathrm{ug} / \mathrm{ml}$ safe stain(EB) (Sigma-Aldrich, MO, USA) for $1 \mathrm{~h}$. DNA and RNA ladders were visualized and photographed under the transmitted ultraviolet light.

\section{Statistical Analysis}

Results were expressed as the mean \pm standard deviation. Data were analyzed using GraphPad Prism statistical software 6.0 (GraphPad Software, La Jolla, CA, USA) using either Paired Samples t-Test or two-way ANOVA where appropriate. $\mathrm{P}<0.05$ was considered statistically significant.

\section{Results}

\section{Induction of Syngeneic Animal Model of Breast Cancer}

Metastatic animal model of triple-negative breast cancer was generated after 35 days of tumor induction in Balb/c mice (Fig. 1a). H\&E staining and pathological confirmation were performed on tumor tissues (Fig. 1 b, c, d, and e).

\section{Primary and Metastatic Tumor Cells Extraction}

We properly extracted primary and lung metastatic tumor cells from subcutaneous primary tumor and lung of cancerous mice, respectively. The metastatic tumor cells in the lung, after primary isolation, form colonies in the culture medium. Due to the high rate of growth and proliferation, the tumor cells in these colonies are purified after several passages. These metastatic tumor cells are called 4T1L, while tumor cells that are obtained in the same way as the original tissue of the tumor called 4T1P (Fig. 1f, g).

\section{Down-regulation of DR-5 in Metastatic Tumor Cells} Apoptotic cell death is related to the activation of regulatory genes. Therefore, the expression level of its related genes was measured. The expression of DR- 5 as an execution factor of apoptosis was analyzed in $4 \mathrm{~T} 1 \mathrm{~L}$ and 4T1P. Total RNA extraction, cDNA synthesis, and real-time qPCR were done as described in material and methods. The quality, yield, and size of extracted RNA, synthesized cDNA and PCR products were confirmed using nanodrop and gel electrophoresis (Fig. 2a, b). The expression of DR-5 was significantly down-regulated in 4T1L compared with 4T1P (Fig. 2c). These results suggest that DR-5 has a significant role in the apoptosis resistance of metastatic tumor cells.

\section{Discussion}

A decreased sensitivity to apoptosis induction plays critical roles in tumorigenesis, invasion, metastasis, and chemoresistance of breast cancers. Many questions regarding apoptosis resistance in breast cancer remain to be answered.[6] Apoptosis, a form of programmed cell death, requires the cascaded activation of caspases. Activation of procaspases resulted from two major pathways, intrinsic and extrinsic. The extrinsic pathway is associated with death receptors.[8] Among the six different death receptors (DRs) identified to date, DR-4 and DR-5 are selectively expressed 


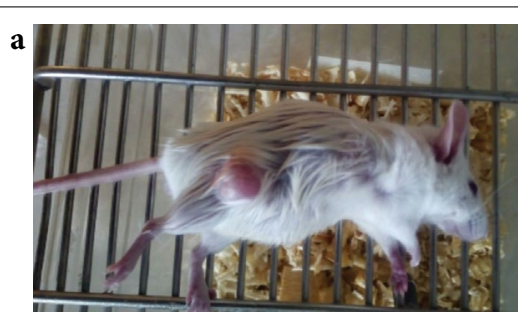

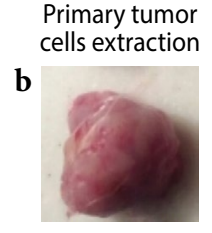
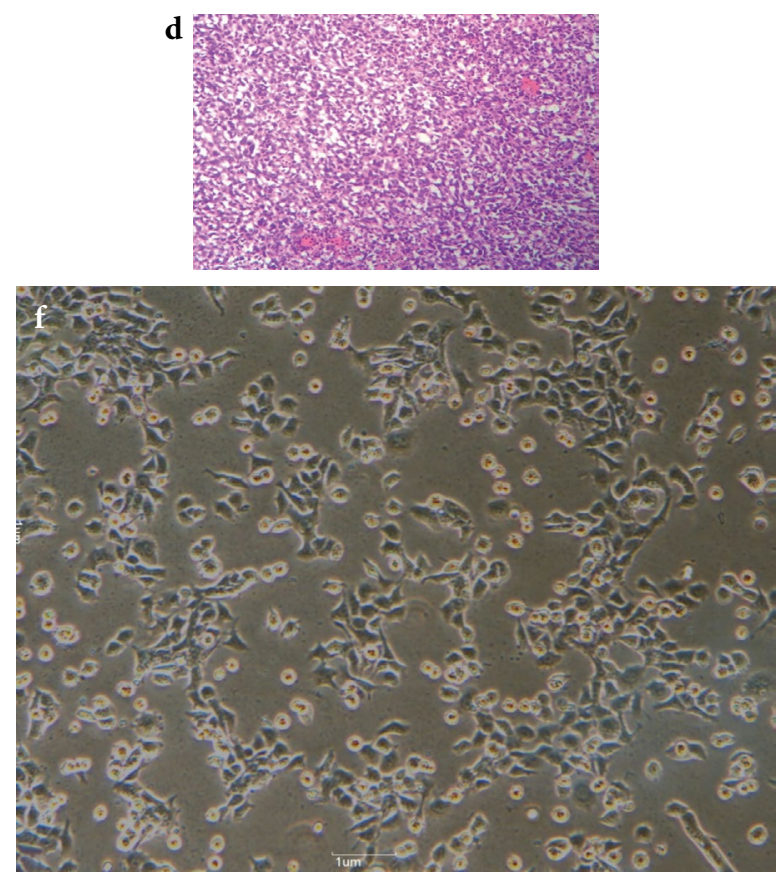

Metastatic tumor cells extraction

c

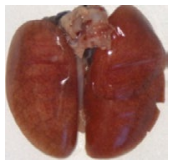

Fig. 1. Primary and lung metastatic tumor cells extraction. (a) Metastatic animal model of triple-negative breast cancer was generated after 35 days of tumor induction in Balb/c mice. (b, c) primary tumor and lung of cancerous mice removed. (d, e) H\&E staining and pathological confirmation were performed on tumor tissues. (f, g) Primary and metastatic tumor cells were extracted from subcutaneous tumor and lung of cancerous mice, respectively.

on cancer cells. Therefore, unlike chemotherapeutic agents, these receptors can potentially mediate the selective killing of tumor cells.[14] DR-5 is well known to mediate apoptosis upon ligation with its ligand or induction of its clustering or aggregation (e.g., with an agonistic antibody or overexpression). Targeting the DR-5 extrinsic apoptotic pathway has become an attractive cancer treatment strategy.[15] It has been documented that metastatic cells are more resistant to apoptosis.[6] However, to date, the precise mechanism of this resistance has not been clearly addressed. To our knowledge, in this study, DR-5 gene expression in the metastatic tumor cells and their ancestors, the primary tumor cells were reviewed for the first time. Results showed that, compared with the primary tumor cells, DR-5 gene expression was significantly down-regulated in metastatic tumor cells.

Current research in TNBC, which is an aggressive subtype of breast cancer, is focused on a greater understanding of the response and resistance to treatment, including the role of apoptosis.[16] Despite a variety of available approaches for the treatment of metastatic TNBC, the survival rate of patients remains very low. In TNBC, metastasis and chemo-resistance are the most 


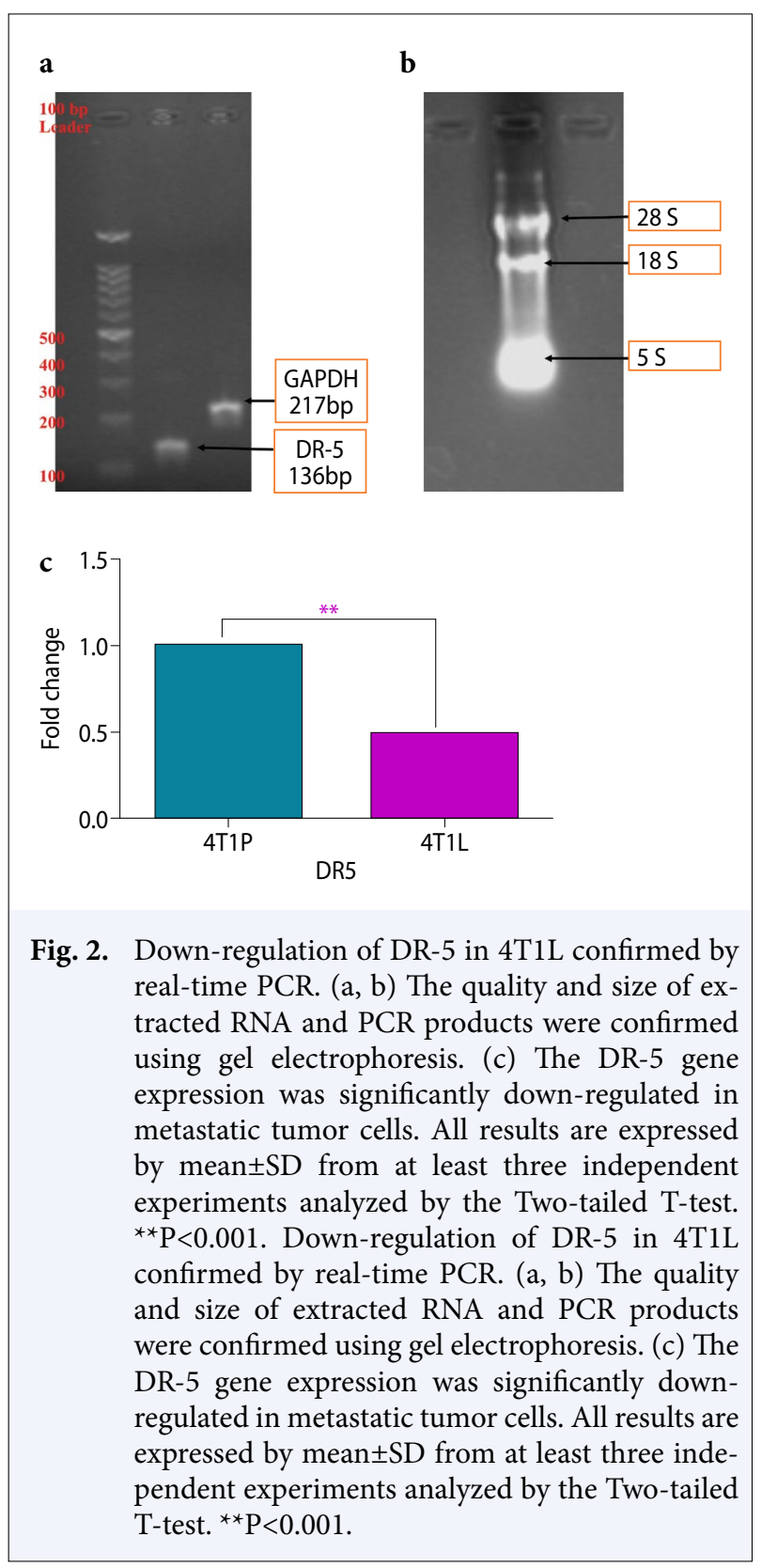

common causes of treatment failure. Elucidating the underlying mechanisms is crucial to developing novel therapeutic strategies.[17] The result of the present study elucidates that DR-5 gene expression down-regulated in the metastatic cascade of TNBC and this can be a major reason for apoptotic resistance of metastatic tumor cells.

It is unclear whether DR-5 indeed plays a role in the regulation of cancer invasion and metastasis in humans. In some human cancer, such as breast, lung or renal cell cancer, results indicate that DR5 is overexpressed and significantly correlated with more ag- gressive tumor behavior and poor survival of cancer patients. [18-20] In other cancer (e.g., in the bladder or colorectal cancer) results show that DR-5 expression is associated with a less aggressive phenotype and better survival.[21,22] In other cancer (e.g., in the bladder or colorectal cancer) results show that DR-5 expression is associated with a less aggressive phenotype and better survival. [23,24]

Our result showed that DR-5 down-regulated in the metastatic cascade of TNBC. In compliance with our results, research on human cancer cell lines showed that inhibition of DR- 5 by knockdown or knockout increased invasion of cell lines. Strikingly, knockdown of DR-5 expression significantly increased lung metastasis of cancer cells in a nude mouse subcutaneous lung cancer xenograft model.[25]

DR-5 Mutations have been identified in various human tumors.[26-30] In breast cancer, approximately $12 \%$ of inactivating mutations in DR-5 was diagnosed only in metastatic type.[26] It has been shown that DR-5 deficiency in mice enhances lymph node metastasis of skin carcinoma [31] and metastasis of lymphoma cells to liver and lung.[32] It has been shown that the DR-5 agonistic antibody lexatumumab robustly suppresses lymph node or lung metastasis in an orthotopic model of TNBC.[33]

\section{Conclusion}

In conclusion, the results of this research demonstrated that compared with the primary tumor cells, DR-5 gene expression was significantly down-regulated in metastatic tumor cells, and consequently, these cells are more prone to apoptotic resistance. These findings support the notion that DR-5 may be associated with the suppression of cancer metastasis and down-regulation of this receptor in tumor cells strategies to invade and metastasis. Consequently, the findings obtained in this study will highly likely to provide the basis for designing targeted therapeutic methods to combat metastatic TNBC.

Acknowledgments: We want to especially thank Dr. Naser Ahmadbeigi for his practical advisation and helpful information about metastatic breast cancer.

Peer-review: Externally peer-reviewed.

Conflict of Interest: The author declares that they have no competing interests.

Ethics Committee Approval: All animal experiments were in compliance with the relevant laws and were ap- 
proved by the Ethics Committee of the Tehran University of Medical Sciences (Registration number: IR.TUMS. REC.1394.1439).

Financial Support: This work was supported by a grant from the Tehran University of Medical Sciences (TUMS) Grant No 95-03-87-33016.

\section{References}

1. Yao H, He G, Yan S, Chen C, Song L, Rosol TJ, et al. Triple-negative breast cancer: is there a treatment on the horizon? Oncotarget 2017;8(1):1913-24.

2. Isakoff SJ. Triple-negative breast cancer: role of specific chemotherapy agents. Cancer J 2010;16(1):53-61.

3. Acharyya S, Oskarsson T, Vanharanta S, Malladi S, Kim J, Morris PG, et al. A CXCL1 paracrine network links cancer chemoresistance and metastasis. Cell 2012;150(1):165-78.

4. Gonzalez-Angulo AM, Morales-Vasquez F, Hortobagyi GN. Overview of resistance to systemic therapy in patients with breast cancer. Breast Cancer Chemosensitivity. Springer; 2007. p. 1-22.

5. Wilson T, Johnston P, Longley D. Anti-apoptotic mechanisms of drug resistance in cancer. Current cancer drug targets 2009;9(3):307-19.

6. Yang L. Mechanisms of Apoptosis Resistance In Breast Cancer. In: Piccart HM, Solin LJ, Cardoso F, Wood WC, editors. Breast Cancer and Molecular Medicine. Berlin, Heidelberg: Springer: 2006. p. 841-58.

7. Martin SJ, Green DR. Apoptosis and cancer: the failure of controls on cell death and cell survival. Crit Rev Oncol Hematol 1995;18(2):137-53.

8. Igney FH, Krammer PH. Death and anti-death: tumour resistance to apoptosis. Nature Reviews Cancer 2002;2(4):277.

9. Srivastava RK. TRAIL/Apo-2L: mechanisms and clinical applications in cancer. Neoplasia 2001;3(6):53546.

10. Valastyan S, Weinberg RA. Tumor metastasis: molecular insights and evolving paradigms. Cell. 2011;147(2):275-92.

11.Lujambio A, Calin GA, Villanueva A, Ropero S, Sánchez-Céspedes M, Blanco D, et al. A microRNA DNA methylation signature for human cancer metastasis. Version 2. Proc Natl Acad Sci U S A 2008;105(36):13556-61.

12. Ventura A, Jacks T. MicroRNAs and cancer: short RNAs go a long way. Cell 2009;136(4):586-91.

13. Cameron MD, Schmidt EE, Kerkvliet N, Nadkarni KV, Morris VL, Groom AC, et al. Temporal progression of metastasis in lung: cell survival, dormancy, and location dependence of metastatic inefficiency. Cancer research 2000;60(9):2541-6.
14. Prasad S, Kim JH, Gupta SC, Aggarwal BB. Targeting death receptors for TRAIL by agents designed by Mother Nature. Trends Pharmacol Sci 2014;35(10):520-36.

15. Wang G, Wang X, Yu H, Wei S, Williams N, Holmes DL, et al. Small-molecule activation of the TRAIL receptor DR5 in human cancer cells. Nat Chem Biol 2013;9(2):84-9.

16. Haffty BG, Yang Q, Reiss M, Kearney T, Higgins $\mathrm{SA}$, Weidhaas J, et al. Locoregional relapse and distant metastasis in conservatively managed triple negative early-stage breast cancer. J Clin Oncol 2006;24(36):5652-7.

17. Davuluri G, Schiemann WP, Plow EF, Sossey-Alaoui K. Loss of WAVE3 sensitizes triple-negative breast cancers to chemotherapeutics by inhibiting the STAT-HIF-1 $\alpha$-mediated angiogenesis. JAKSTAT 2015;3(4):e1009276.

18. Spierings DC, de Vries EG, Timens W, Groen HJ, Boezen HM, de Jong S. Expression of TRAIL and TRAIL death receptors in stage III non-small cell lung cancer tumors. Clin Cancer Res 2003;9(9):3397-405.

19. Macher-Goeppinger S, Aulmann S, Tagscherer KE, Wagener N, Haferkamp A, Penzel R, et al. Prognostic value of tumor necrosis factor-related apoptosis-inducing ligand (TRAIL) and TRAIL receptors in renal cell cancer. Clin Cancer Res 2009;15(2):650-9.

20. Ganten TM, Sykora J, Koschny R, Batke E, Aulmann S, Mansmann U, et al. Prognostic significance of tumour necrosis factor-related apoptosis-inducing ligand (TRAIL) receptor expression in patients with breast cancer. J Mol Med (Berl) 2009;87(10):995-1007.

21. Uddin S, Hussain AR, Ahmed M, Al-Sanea N, Abduljabbar A, Ashari LH, et al. Coexpression of activated c-Met and death receptor 5 predicts better survival in colorectal carcinoma. Am J Pathol 2011;179(6):303244.

22. Li Y, Jin X, Li J, Jin X, Yu J, Sun X, et al. Expression of TRAIL, DR4, and DR5 in bladder cancer: correlation with response to adjuvant therapy and implications of prognosis. Urology 2012;79(4):968.e7-15.

23. Duiker EW, van der Zee AG, de Graeff P, Boersmavan Ek W, Hollema $H$, de Bock GH, et al. The extrinsic apoptosis pathway and its prognostic impact in ovarian cancer. Gynecol Oncol 2010;116(3):549-55.

24. Maduro JH, Noordhuis MG, ten Hoor KA, Pras E, Arts HJ, Eijsink JJ, et al. The prognostic value of TRAIL and its death receptors in cervical cancer. Int J Radiat Oncol Biol Phys 2009 1;75(1):203-11.

25. Oh YT, Yue P, Wang D, Tong JS, Chen ZG, Khuri FR, et al. Suppression of death receptor 5 enhances cancer cell invasion and metastasis through activation of caspase-8/TRAF2-mediated signaling. Oncotarget 2015;6(38):41324-38. 
26. Shin MS, Kim HS, Lee SH, Park WS, Kim SY, Park JY, et al. Mutations of tumor necrosis factor-related apoptosis-inducing ligand receptor 1 (TRAIL-R1) and receptor 2 (TRAIL-R2) genes in metastatic breast cancers. Cancer Res 2001;61(13):4942-6.

27. Lee SH, Shin MS, Kim HS, Lee HK, Park WS, Kim SY, et al. Alterations of the DR5/TRAIL receptor 2 gene in non-small cell lung cancers. Cancer Res 1999;59(22):5683-6.

28. Pai SI, Wu GS, Ozören N, Wu L, Jen J, Sidransky D, ElDeiry WS. Rare loss-of-function mutation of a death receptor gene in head and neck cancer. Cancer Res 1998;58(16):3513-8.

29. Lee SH, Shin MS, Kim HS, Lee HK, Park WS, Kim SY, et al. Somatic mutations of TRAIL-receptor 1 and TRAIL-receptor 2 genes in non-Hodgkin's lymphoma. Oncogene 2001;20(3):399-403.
30. Park WS, Lee JH, Shin MS, Park JY, Kim HS, Kim YS, et al. Inactivating mutations of KILLER/DR5 gene in gastric cancers. Gastroenterology 2001;121(5):121925.

31. Grosse-Wilde A, Voloshanenko O, Bailey SL, Longton GM, Schaefer U, Csernok AI, et al. TRAIL-R deficiency in mice enhances lymph node metastasis without affecting primary tumor development. Version 2. J Clin Invest 2008;118(1):100-10.

32. Finnberg N, Klein-Szanto AJ, El-Deiry WS. TRAIL-R deficiency in mice promotes susceptibility to chronic inflammation and tumorigenesis. J Clin Invest 2008;118(1):111-23.

33. Malin D, Chen F, Schiller C, Koblinski J, Cryns VL. Enhanced metastasis suppression by targeting TRAIL receptor 2 in a murine model of triple-negative breast cancer. Clin Cancer Res 2011;17(15):5005-15. 